\title{
A CASE OF HUNTINGTON'S DISEASE WHEN PSYCHIATRY PRESENTS BEFORE NEUROLOGY
}

${ }^{1}$ Diana Amorim Pires, ${ }^{1}$ Filipa Caldas, ${ }^{1}$ Margarida Barros, ${ }^{1}$ Pedro Gonçalves Frias, ${ }^{1}$ Rodrigo Valido, ${ }^{2}$ Paulo Horta, ${ }^{3}$ Ana Paula Correia

1 - Psychiatry Residents, 2 - Psychiatrist, 3 - Neurologist. Hospital de Magalhães Lemos, Oporto, Portugal.

OBJECTIVES Raise awareness of the tenuous barrier between psychiatric and neurological pathology, and their common coexistence, through a clinical case of Huntington's disease.

BACKGROUND AND AIMS Huntington's disease (HD) is an autosomal dominant neurodegenerative syndrome characterized by a triad: progressive hyperkinetic movement disorder, neuropsychiatric disturbances, and cognitive deterioration. Its diagnosis is based on the presence of involuntary choreiform movements and positive genetic testing. However, it's known that psychiatric and cognitive symptoms may appear decades before the motor abnormalities (premotor phase), and thus these patients may present initially to psychiatric care. Family history may provide important clues to diagnosis.

Knowing this, a new pathway is open for the development of progression-delay interventions, especially important for relatives with positive testing before symptoms commencement, and a multidisciplinary follow-up becomes mandatory.

METHODS Clinical case description and literature review through a bibliographic research in Pubmed database.

\section{CLINICAL CASE DESCRIPTION}

\section{A 64-years old Caucasian woman, married with three adult sons.}

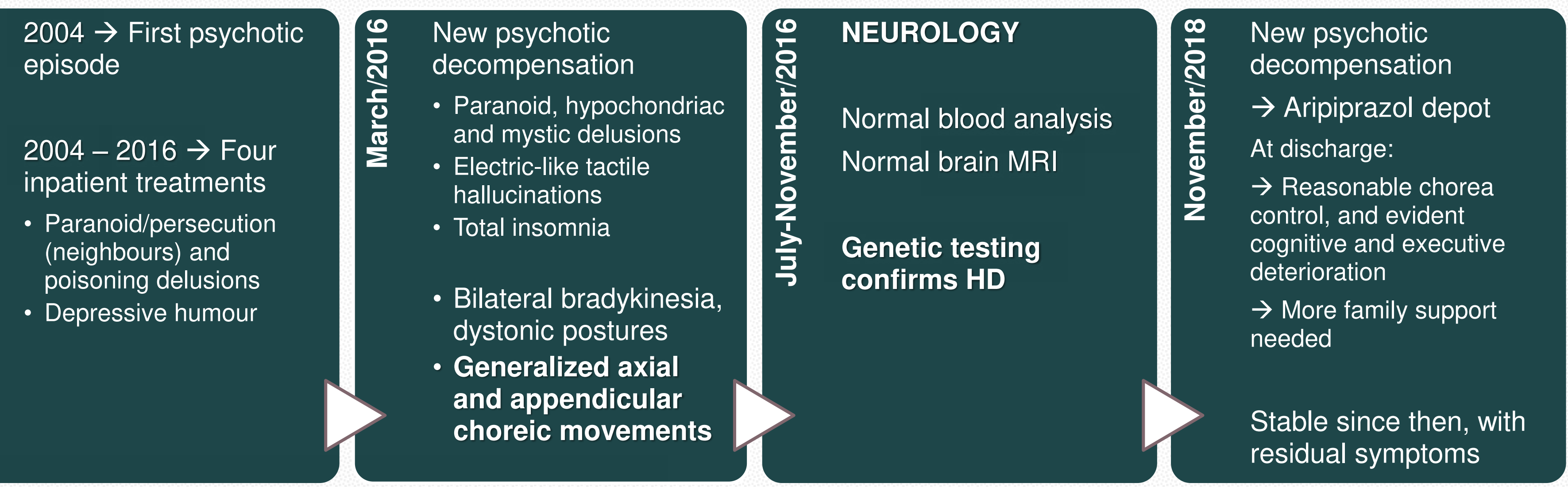

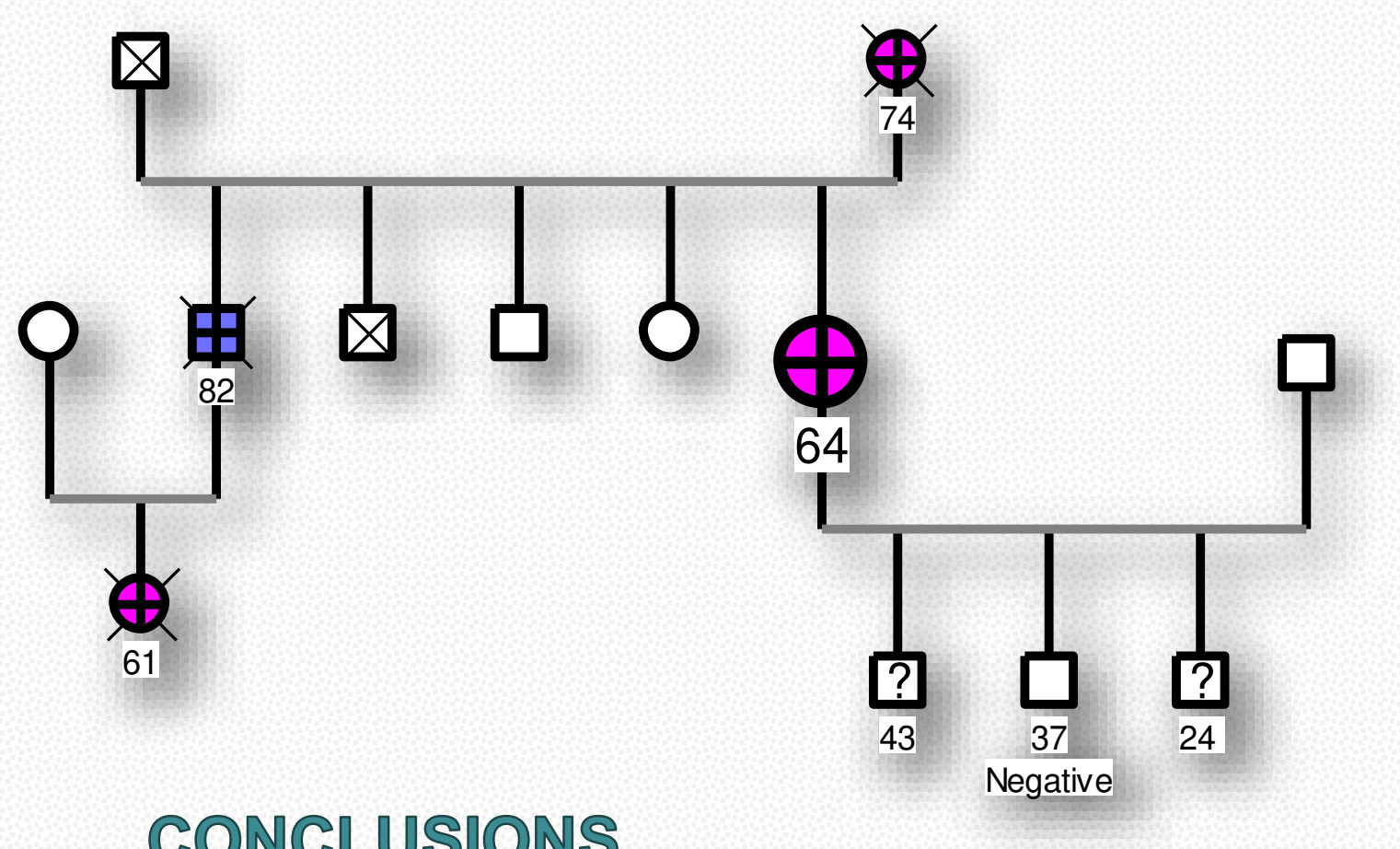

When first diagnosed (2016), no family history of movement or psychiatric disorders was known.

Posteriorly...

$\rightarrow \mathrm{A}$ brother and a niece developed HD and both died of complications

$\rightarrow$ It was suspected that her mother had HD disease with psychiatric manifestations as well

$\rightarrow$ One son tested negative for HD, the others refused to be tested

\section{CONCLUSIONS}

- Awareness must be paid to the possible mingle of psychiatric and neurologic disorders - in this case, what appeared to be a psychiatric disorder later became a complex and devastating neurodegenerative disease.

- A timely, in premotor phase or prior, and a multidisciplinary intervention of Huntington's disease is crucial, for symptomatic control and progression's prevention.

- Family history is an important clue to these neurodegenerative diseases, and new tools of early detection are needed.

- Relatives benefit from genetic counselling, and neuroprotective, preventive and disease-modifying therapies are required.

\section{Bibliography}

Kim, S.D., \& Funga, V. S. C. (2014). An update on Huntington's disease: from the gene to the clinic. Curr Opin Neurol, 27, 477-483.

Ramos, A.R.S., \& Garrett, C. (2017). Huntington's Disease: Premotor Phase. Neurodegener Dis, 17, 313-322.

Haa, A.D., \& Funga, V.S.C. (2012). Huntington's disease. Curr Opin Neurol, 25, 491-498. 